\title{
A Study on Drug Utilization Pattern in Dermatology Outpatient Department in a Tertiary Care Teaching Hospital Of North East India
}

\author{
Authors \\ Dr Indrani Bhagawati, Dr Pradumna Pathak \\ Department of Pharmacology, Fakhruddin Ali Ahmed Medical College and Hospital \\ Barpeta, Assam, India, PIN: 781301 \\ Corresponding Author \\ Dr Pradumna Pathak \\ Department of Pharmacology, Fakhruddin Ali Ahmed Medical College and Hospital \\ Barpeta, Assam, India, PIN: 781301 \\ Email: drpradumnapathak@gmail.com, Mobile No: +91-8876051271
}

\begin{abstract}
Introduction: Drug utilization as a research area made it possible to study drug prescribing and drug usage in a scientific and formal manner. This type of study of prescribing pattern is a part of the medical audit and seeks to monitor, evaluate and if necessary suggest modification in prescribing practices to make medical care rational and cost effective.

Objectives: The purpose of the present study was to analyze the prescribing pattern in dermatology outpatient department for a quantitative analysis.

Methodology: This study was a prospective observational study conducted on patients attending the dermatology OPD. A random once weekly data collection was done for 4 months duration. Patients of all ages and both sexes were included in the study. Informed consent was obtained verbally from the patient or legal guardian. Patient related information and drug-related information (like dose, dosage form, route of administration) was recorded on a data collection sheet. The data obtained was analysed and presented with appropriate statistical methods.
\end{abstract}

Results: Antihistaminic was found to be the most commonly prescribed class of drugs while Levocetirizine was most prevalently used antihistaminic. A total of 449 drugs were prescribed in 132 patients meaning there were 3.4 drugs per prescription.

Key Words: Drug utilization, Dermatology, Fixed dose combination, Prescriptions, Outpatients

\section{INTRODUCTION}

There are more effective drugs today on the market than ever before. Patients are better educated, have greater expectations from health care, and frequently use multiple sources of health care. Yet, drugs are frequently not used to their full potential or according to the generally accepted criteria. All prescribing is not necessarily based on patient needs and all patient needs are not necessarily met with drug therapy. Consequently, there is as much concern about inappropriate and expensive prescribing, as about under prescribing. The development of drug utilization as a research area made it possible to 
study drug prescribing and drug usage in a scientific and formal manner ${ }^{[1,2]}$. The World Health Organisation (WHO) defines drug utilization as the marketing, distribution, prescription and the use of drugs in a society, with special emphasis on the resulting medical, social and economic consequences ${ }^{[3]}$. This type of study of prescribing pattern is a part of the medical audit and seeks to monitor, evaluate and if necessary suggest modification in prescribing practices to make medical care rational and cost effective ${ }^{[4,5,6]}$. Since no such study has been carried out selectively in this part of the region in such a newly established medical college and hospital, this study is being carried out to obtain data for promoting rational drug use. The data of the present study can also be used to produce crude estimates of disease prevalence and to plan drug distribution ${ }^{[7,8]}$.

Table No 1: Data collection sheet queries

\begin{tabular}{|l|c|c|}
\hline Hospital number & Occupation & Fixed dose combination used \\
\hline Date & Income & Whether $\mathrm{R}_{\mathrm{x}}$ is written in the prescription \\
\hline Age & Diagnosis & Signature of the prescriber \\
\hline Address & Name of prescribed drug(s) & Average consultation time \\
\hline Education & $\begin{array}{c}\text { Total number of drugs used in the } \\
\text { prescription }\end{array}$ & Average dispensing time \\
\hline Marital status & Route of administration of each drug & Patients knowledge about correct dosage \\
\hline
\end{tabular}

The consultation time, which is the time the dermatologist spent with the patient in the process of consultation, examination and prescribing is noted by the investigator using the stop watch and recorded ${ }^{[9,10,11,12]}$.

Inclusion criteria: All patients attending the Dermatology OPD.

Exclusion criteria: (i) Patients referred from other departments for dermatology opinion.

(ii)Alimentary product, toothpaste, vaccine, diagnostic products.

(iii) Patient with Leprosy (as they are having separate cards)

\section{AIM AND OBJECTIVES}

The purpose of the study is to analyse the prescribing pattern in dermatology out patient department and to do a quantitative analysis of overall drug use.

\section{METHODOLOGY}

This study is a prospective observational study conducted on patients attending the dermatology out patient department (OPD). A random once weekly data collection is done for 4 months duration. Patients of all ages and both sexes are included in the study. In-patients, referred patients from other departments are excluded from the study. Informed consents are obtained verbally from the patient or legal guardian. Patient related information (like age, sex) and drug-related information (like dose, dosage form, route of administration) is recorded on a data collection sheet containing the following queries as shown in Table No 1.
Ethical approval: The institutional ethical committee approval is taken before conducting the study. The approval number is Ethical Committee/128/2012/5681 dated 04/12/2015.

As it is a non-interventional study and for assurance to the institutional ethics committee regarding the confidentiality of the subjects, the following steps would be taken:

1. Identification of patients by the hospital number only and not by name.

2. Prescriptions are to be accessed by investigators in the Dermatology OPD and Hospital dispensary only. 
3. Patient details will not be disclosed to any party other than the co-investigators.

Statistical Analysis: Descriptive statistical analysis is carried out in the present study. The results on the continuous measurements are presented as Mean \pm Standard Deviation and the results on the categorical measurements are presented as Number (\%).

\section{RESULTS}

Out of 132 cases the male patients (52.27\%) outnumbered the female and the mean age was found to be $19.28 \pm 2.6$ years. $61.36 \%$ patients belong to middle socio-economic group. Majority of the patients were students $(53.78 \%)$ by occupation. Out of all the cases studied $71.21 \%$ were unmarried and non-vegetarian (78.78\%). Fungal skin infections were found to be the most common (21.21\%) skin condition in this study. A total of 449 drugs were prescribed, meaning there were 3.4 drugs per prescription. Out of 449 drugs, most commonly topical preparation $(49.22 \%)$ was used than oral $(44.09 \%)$ and injectables $(6.68 \%)$. An $84.84 \%$ of oral formulations were single and rest $15.15 \%$ were in combinations. In topical formulations $71.94 \%$ and $28.05 \%$ were single and combined preparations respectively. There was no combination of drugs used among the injectables. Brand names were used in $63.69 \%$. Drugs in accordance with classes of drugs are: (i) Antihistaminic (28.5\%), where Levocetirizine was most commonly prescribed; (ii) Anti-fungals (22.49\%), Fluconazole was most commonly used; (iii) Antibiotics (18.26\%), Cefixime was most commonly prescribed; (iii) Steroid (17.37\%); (iv) Miscellaneous (13.36\%), most common was Permethrin.
Fig. 1: Classes of drugs used in Dermatology OPD

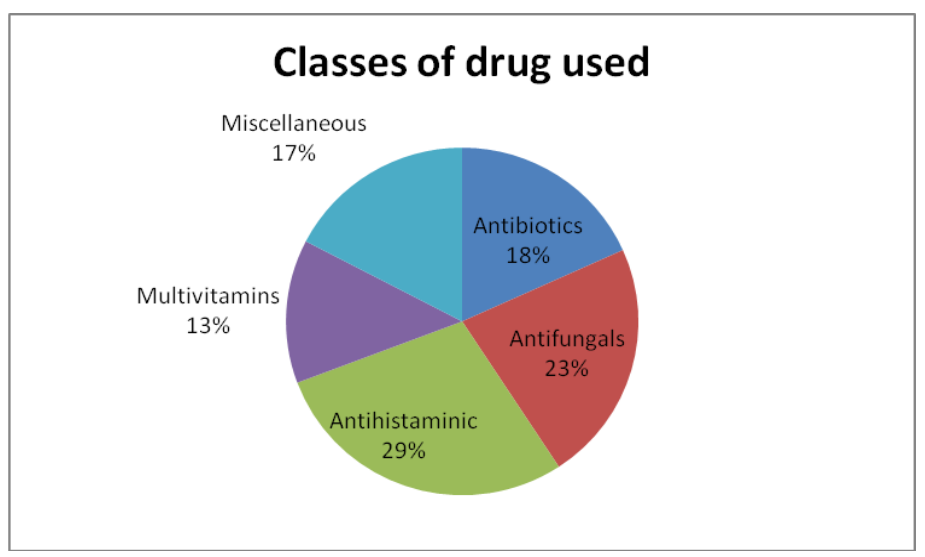

The average consultation time was calculated to be $3.4 \pm 1.2$ minutes and average dispensing time $4.6 \pm 2.2$ minutes. In all $(100 \%)$ cases $\mathrm{Rx}$ was found to be written and prescribers put their signatures. Most (90.9\%) patients and their attendants/guardians had proper knowledge of drugs dosing pattern.

\section{DISCUSSION}

The WHO indicators are used to focus on the local health problem. Both the prescribing and patient care indicator was measured in the same patients so that to give a better idea of the total service individual patients were receiving ${ }^{[13]}$.

Average 3.4 drugs per prescription, which showed a remarkable restraint on prescribing and an awareness to avoid polypharmacy. Average consultation time was found to be $3.4 \pm 1.2$ minutes which seemed to be satisfactory when compared with similar study conducted by Maini $\mathrm{R}$ et al ${ }^{[9]}$. The mean age was calculated to be $19.28 \pm 2.6$ years which was comparable to study by Kumar $S$ et al where it was $21.67 \pm 0.51^{[14]}$.

Drugs prescribed in brand names account for $63.69 \%$, which could result in more expensive prescribing because usually the branded drugs are costlier. Moreover brand names can create confusion during dispensing. Prescription in generic names should be increased further to provide cheaper and safer treatment ${ }^{[9]}$.

FDCs (fixed dose combination) were $15.15 \%$ of the oral formulations; $28.05 \%$ of topical formulations. The chronic nature of some of the 
dermatological conditions and the multi-modality approach being used makes the use of fixed dose combinations an inevitable option. The use of fixed dose combination may help to reduce the cost and improve patient compliance ${ }^{[14]}$.

Antibiotics are amongst the most important drugs, but commonly overused or abused and costly forms of therapy. In India the prevalence of use of antimicrobial agents varies from $24-60 \%{ }^{[9]}$. In the present study the number of encounters with antibiotics was $18.26 \%$ prescriptions.

Among the total number of drugs prescribed, most of them were prescribed by the topical route followed by oral and injectable routes; this is in accordance to a study conducted by Tikoo D et al [15].

Analysis showed that antihistamines were the most commonly prescribed systemic agents in dermatology because of disease prevalence with related symptoms of itching (associated with fungal infection, scabies and eczema) ${ }^{[16]}$. In the present study antihistaminic $(28.5 \%)$ was found to be the maximally used class of drugs and out of which Levocetirizine was most commonly used among all the antihistaminics.

\section{LIMITATIONS}

Since the study duration was 4 months so this study result may not reflect the drug usage pattern during seasonal dermatological disease outbreak. The other important limitations of this study were the lack of facility indicators (like the availability of key drugs, availability of copy of essential drugs list or formulary) and the impact of cost on the drug treatment, which could have increase the utility of the study. As like other drug utilization studies, it was not possible to monitor the actual use or compliance with the prescribed drugs.

\section{STRENGTHS OF THIS STUDY}

The strengths of this study are the prospective use of a structured proforma for data collection with the details of drug prescriptions. Moreover there was a comprehensive application of drug utilization study tools like the Prescribing indicators (like average no of drugs per prescription, antibiotics usage), Patient care indicator (like average consultation time, average dispensing time). Another strength is concomitant presentation of data on dermatological disease prevalence in this study.

\section{CONCLUSION}

Considering the results of the above study it can be suggested that, there is an urgent need to emphasize rational and complete prescribing in the undergraduate and postgraduate medical curriculum. The topic of rational prescribing should be well-defined and well-advocated, its conduct and importance should be systematically taught/ imparted to the medical undergraduate. This audit report is aimed at providing feedback to the drug prescribers and such periodic audit of drug prescribing is desirable in rationalizing prescribing practices.

The study also suggests that the prescribing pattern of drugs in Dermatology OPD of this tertiary care rural teaching hospital is appropriate and according to the guidelines but there is a need to emphasize to all the prescribers to adhere to the prescription format, mainly to keep the number of drugs per prescription low. Various intervention strategies like introduction of hospital formulary and prescription control like setting a level upto which a particular prescriber can be permitted to prescribe anti-microbial, immunosuppressant etc by institutional regulatory authorities should be planned. But the involvement of clinical pharmacist in clinical practice should be increased for the proper usage of medication and better outcome.

\section{ACKNOWLEDGEMENT}

The authors wish to express their sincere thanks to Dr Bornali Dutta, Assistant Professor of Dermatology of Fakhruddin Ali Ahmed Medical College Hospital, Barpeta for allowing the study to be conducted in clinics of department of Dermatology. The authors would also like to 
thank all the patients and their guardians/ attendants who agreed to participate in the study.

\section{REFERENCES}

1. Truter I. A review of drug utilization studies and methodologies. Jordan journal of pharmaceutical sciences 2008. Vol 1 No 2. Page no: 91-104.

2. Laporte JR, Porta M, Capella D. Drug utilization studies: a tool for determining the effectiveness of drug use. $\mathrm{Br} \mathrm{J}$ clin Pharmac 1983. Vol 16. Page no: 301-304.

3. World Health Organization. Introduction to drug research. Oslo. World Health Organization 2003.

4. Venkateswaramurthy N, Murali R, Kumar RS. The study of drug utilization pattern in pediatric patients. International Journal of Pharmacy and Pharmaceutical Sciences 2013; Vol 5 No 3. Page no: 140-144.

5. Pesic G, Jovic Z, Vasic K. Medicine and Biology 2005. Vol 12 No 3. Page No: 174178.

6. Shalini S, Ravichandran V, Mohanty BK, Dhanaraj SK, Saraswathi R. Drug utilization studies- an overview. International journal of pharmaceutical science and nanotechnology April-June 2010. Vol 3 Issue 1. Page no: 803-810.

7. Gama H. Drug utilization studies. Arqui Med 2008. Vol 22 Issue 2/3. Page No: 6974.

8. Jyothi K, Babu JD. Drug utilization evaluation of cephalosporins in general medicine units of rural tertiary care hospital. International journal of current pharmaceutical research (Inter J Curr Pharm Res) 2012. Volume 4 Issue 2. Page no: 88-91.

9. Maini R, Verma KK, Biswas NR, Agarwal SS. Drug utilization study in Dermatology in a tertiary hospital in Delhi. Indian $\mathbf{J}$ Physiol Pharmacal 2002. Vol 46 No 1. Page no: 107-110.
10. Lahon K, Shetty HM, Paramel A, Sharma G. A Retrospective Drug Utilization Study of Antidepressants in the Psychiatric Unit of a Tertiary Care Hospital. Journal of Clinical and Diagnostic Research October 2011. Vol 5 Issue 5. Page no: 1069-1075.

11. Rajathilagam T, Sandozi T, Rajagopalan V, Rani RJ. A study of prescribing pattern of antifungal drugs in dermatology outpatient (OPD) of a tertiary care hospital. International journal of Biological \& Pharmaceutical Research 2012. Vol 3 Issue 8. Page no: 968-973.

12. Abdi SAH, Churi S, Kumar YSR. Study of drug utilization pattern of antihypertensive agents in a south Indian tertiary care teaching hospital. Indian Jornal of Pharmacology April 2012. Vol 44 Issue 2. Page no: 210-213.

13. Karande S, Sankhe P, Kulkarni M. Patterns of prescription and drug dispensing. Indian Journal of Pediatrics February 2005. Vol 72. Page no: 117-121.

14. Kumar S, Dutta S, Beg MA, Mehta AK, Anjoom M, Sindhu S. Drug utilization pattern in acne vulgaris in skin outpatients departmet of a tertiary care teaching hospital at Dehradun, Uttarakhand. International journal of medical science and public health 2014. Vol 3 Issue 7.

15. Tikoo D, Chopra SC, Kaushal S, Dogra A. Evaluation of drug use pattern in dermatology as a tool to promote rational prescribing. JK science July-September 2011. Vol 13 No 3. Page no: 128-131.

16. Sarkar C, Das B, Sripathi H. Drug prescribing pattern in dermatology in a teaching hospital in western Nepal. Journal of Nepal Medical Association January-March 2002. Vol 41. Page no: 241-246. 